\title{
Dose-dependent effects of cisplatin on the severity of testicular injury in Sprague Dawley rats: reactive oxygen species and endoplasmic reticulum stress
}

\author{
This article was published in the following Dove Press journal: \\ Drug Design, Development and Therapy \\ 12 December 2016 \\ Number of times this article has been viewed
}

\author{
Kiran Kumar Soni ${ }^{1}$ \\ Hye Kyung Kim² \\ Bo Ram Choi \\ Keshab Kumar Karna' \\ Jae Hyung You' \\ Jai Seong Cha' \\ Yu Seob Shin' \\ Sung Won Lee $^{3}$ \\ Chul Young Kim ${ }^{4}$ \\ Jong Kwan Park' \\ 'Department of Urology, Institute \\ for Medical Sciences, Chonbuk \\ National University Medical School - \\ Biomedical Research and Institute \\ and Clinical Trial Center for Medical \\ Devices, Chonbuk National University \\ Hospital, Jeonju, ${ }^{2}$ College of Pharmacy, \\ Kyungsung University, Busan, \\ ${ }^{3}$ Department of Urology, Samsung \\ Medical Center, Samsung Biomedical \\ Research Institute, Sungkyunkwan \\ University Medical School, Seoul, \\ ${ }^{4}$ College of Pharmacy, Hanyang \\ University, Ansan, Republic of Korea
}

Correspondence: Jong Kwan Park Department of Urology, Institute for Medical Sciences, Chonbuk National University Medical School - Biomedical

Research and Institute and Clinical

Trial Center for Medical Devices,

Chonbuk National University Hospital,

20, Geonji-Ro, Deokjin-Gu, Jeonju 54909,

Republic of Korea

$\mathrm{Tel}+82632501510$

Fax $+8263250 \quad 1564$

Email rain@chonbuk.ac.kr

\begin{abstract}
Cisplatin (CIS) is used in the treatment of cancer, but its nonspecific systemic actions lead to toxic effects on other parts of the body. This study investigated the severity of CIS toxicity by increasing its dose over a constant time period. Sprague Dawley rats were divided into five treatment groups and control group with CIS (2, 4, 6, 8, and $10 \mathrm{mg} / \mathrm{kg})$ administered intraperitoneally for 5 days. The body and organs were weighed, epididymal sperm was counted, and sperm motility and sperm apoptosis were evaluated. Blood samples were evaluated for complete blood count, reactive oxygen and nitrogen species, malondialdehyde levels, and total testosterone. The testicular tissue was examined for steroidogenic acute regulatory protein and endoplasmic reticulum stress protein. Epididymal sperm was collected for CatSper Western blot. The toxic effects of different doses of CIS on the testis and kidney were compared histologically. The weights of body, testis, epididymis, prostate, seminal vesicle, and kidney; sperm count; sperm motility; steroidogenic acute regulatory protein level; and epididymal sperm count were significantly lower in the CIS-treated groups than in the control group. In contrast, sperm apoptosis, plasma reactive oxygen and nitrogen species, and malondialdehyde, testosterone, red blood cell, hematocrit, hemoglobin, and endoplasmic reticulum stress protein levels all increased. Though CIS effectively treats cancer, at an increased dose it is toxic and life-threatening to the genitourinary system and other parts of the body.
\end{abstract}

Keywords: cisplatin, testicular toxicity, oxidative stress, StAR protein, CatSper, endoplasmic reticulum stress

\section{Introduction}

Cis-diamminedichloroplatinum (II), cisplatin, or cisplatinum (CIS) is an important antineoplastic drug used to treat solid neoplasms, including head, neck, lung, colorectal, hematologic, ovarian, and testicular cancer. ${ }^{1}$ It was approved for use in cancer patients in 1978 by the US Food and Drug Administration. ${ }^{2}$ CIS contains the peculiar atomic configuration of platinum at its core, creating a divalent, inorganic, water-soluble complex. $^{3}$

Although CIS has a chemotherapeutic effect, it has serious side effects on vital organs. ${ }^{4-6}$ However, the mechanisms of CIS-induced nephrotoxicity, hepatotoxicity, and testicular toxicity remain poorly understood. ${ }^{7}$ CIS causes a gradual decrease in renal function that is characterized by significant increases in serum blood urea nitrogen (BUN) levels. ${ }^{8}$ It also increases the red blood cell (RBC) count, hematocrit (Hct), and hemoglobin (Hb) levels within a short period of time. ${ }^{9}$ Animals administered CIS develop severe 
testicular damage characterized by germ cell apoptosis, Leydig cell dysfunction, and testicular steroidogenic disorder. The drug affects spermatogenesis by inhibiting nucleic acid synthesis in germ cells and also inhibits testosterone production by damaging Leydig cells, leading to infertility. ${ }^{10} \mathrm{~A}$ previous experiment found that most rats died when $10 \mathrm{mg} / \mathrm{kg}$ CIS was given to them; therefore, the present study was designed to analyze the effect of different doses of CIS on toxicity and death. ${ }^{11}$

It has been previously reported that free radicals mediate reactions that are responsible for a wide range of CIS-induced side effects. Recently, reactive oxygen species (ROS) have been recognized as being involved in the pathogenesis of CIS-induced testicular toxicity. ${ }^{12}$ CatSper is a voltagegated calcium channel that is expressed in sperm, ${ }^{13}$ and it leads to hyperactivated motility and fertility in male mice. ${ }^{14}$ Therefore, the aim of the present study was to investigate whether an increased dose of CIS has severe effects on the genitourinary system and whether it is related to endoplasmic reticulum (ER) stress.

\section{Materials and methods}

\section{Animals}

This study was approved by the Ethics Committee of Chonbuk National University (Institutional Animal Care and Use Committee) and followed the Basel declaration. Sexually mature male Sprague Dawley (SD) rats aged 9-10 weeks, weighing 300-350 g, were used in the present study. The rats were randomly divided into six groups, each containing ten rats. The rats were fed standard rat chow prepared by Feedlab (Guri, Gyeonggi, South Korea) and had continuous access to water. They were maintained in the animal facility under constant environmental conditions (room temperature $=20^{\circ} \mathrm{C} \pm 2^{\circ} \mathrm{C}$, relative humidity $=50 \% \pm 10 \%$, and 12:12-hour light-dark cycle).

\section{Experimental protocol}

The rats were randomly divided into six groups:

1. Control group (control, $\mathrm{n}=10$ )

2. $2 \mathrm{mg} / \mathrm{kg}$ CIS (CIS-2, $\mathrm{n}=10$ )

3. $4 \mathrm{mg} / \mathrm{kg}$ CIS (CIS-4, $\mathrm{n}=10$ )

4. $6 \mathrm{mg} / \mathrm{kg}$ CIS (CIS-6, $\mathrm{n}=10$ )

5. $8 \mathrm{mg} / \mathrm{kg}$ CIS (CIS- $8, \mathrm{n}=5$ )

6. $10 \mathrm{mg} / \mathrm{kg}$ CIS (CIS-10, $\mathrm{n}=4$ ).

A single dose of CIS was administered intraperitoneally to each group, and the rats were sacrificed after 5 days. They were anesthetized by using a mixture of ketamine $(100 \mathrm{mg} / \mathrm{mL})$ and $2 \%$ Rompun $^{\circledR}(20 \mathrm{mg} / \mathrm{mL})$. The testis, epididymis, seminal vesicle, prostate, and kidney were immediately removed and placed in liquid nitrogen for further analysis.

\section{Chemicals}

CIS was purchased from Ildong Pharmaceutical Co. Ltd. (Seocho-gu, Seoul, Republic of Korea).

\section{Sperm count and motility}

Each epididymis was placed in a separate Eppendorf tube and then minced and suspended in a normal saline at $37^{\circ} \mathrm{C}$ for $5 \mathrm{~min}$. In order to increase the reliability of the sperm count, the total sperm count was calculated by using two or three drops of the sample placed in a counting chamber (SEFIMedical Instruments, Haifa, Israel). Then, the number of sperm heads was counted in ten squares under a light microscope at $20 \times$ magnification. The sperm count was recorded as the concentration of spermatozoa (millions of spermatozoa per $\mathrm{mL}$ ), and the mean was calculated. Sperm motility was evaluated by observing a sperm suspension for $3-5 \mathrm{~min}$. The percentage of motile spermatozoa was determined by using the following formula: (mean number of motile spermatozoa/ total number of spermatozoa) $\times 100 \%$.

\section{Sperm apoptosis}

Apoptotic sperm was analyzed by flow cytometry using a Gallios $^{\mathrm{TM}}$ device (Beckman Coulter, Brea, CA, USA). For each sample, $5 \mu \mathrm{L}$ semen was placed in an Eppendorf tube, to which $100 \mu \mathrm{L}$ binding buffer and $5 \mu \mathrm{L}$ propidium iodide (BD Pharmingen, San Diego, CA, USA) were added. Then, the mixture was incubated at room temperature in the dark for $20 \mathrm{~min}$; following this, $400 \mu \mathrm{L}$ binding buffer was added, and apoptosis was measured within $1 \mathrm{~h}$.

\section{Biochemistry}

Blood was collected from each rat's vena cava, and the samples were sent to the hospital laboratory to obtain the measurements of RBC, Hct, $\mathrm{Hb}, \mathrm{BUN}$, and testosterone levels. Blood samples were centrifuged at 3,500 rpm for $10 \mathrm{~min}$, and the plasma was collected for ROS, reactive nitrogen species (RNS), and malondialdehyde (MDA) analysis.

Plasma ROS/RNS was determined by using the fluorescence kit STA-347 (Cell Biolabs Inc., San Diego, CA, USA) at excitation and emission wavelengths of 480 and $530 \mathrm{~nm}$, respectively, in a SpectraMax Gemini XS Fluorometer. MDA was assessed by using the NWLSSTM assay (Vancouver, WA, Canada).

\section{Histology}

For histologic examination, small pieces of testis and kidney were fixed in formalin and stained with hematoxylin and eosin. Then, the sections were examined under a light microscope to obtain spermatogenic cell density measurements and renal 
injury scores. Spermatogenic cell density was determined by measuring the thickness of the germinal cell layer and the diameter of the seminiferous tubules. ${ }^{11}$ The amount of kidney tubular damage was scored according to the percentage of cortical tubules with epithelial necrosis: 0 , normal; $1, \leq 10 \%$, $2,10 \%-25 \%, 3,26 \%-75 \%$, and $4, \geq 75 \%$. Tubular necrosis was defined as the loss of the proximal tubular brush border, tubular epithelial cell detachment from the basement membrane, or intraluminal aggregation of cells and proteins. ${ }^{15}$

Seminiferous tubules were graded with Johnsen's score from 1 to 10 according to the presence of spermatogenic cells, with a score of 10 equating to complete spermatogenesis with many spermatozoa present. The detailed histologic score criteria are as follows: 1: no seminiferous epithelium; 2: no germinal cells, only Sertoli cells; 3: only spermatogonia; 4: no spermatozoa or spermatids, few spermatocytes; 5 : no spermatozoa or spermatids, many spermatocytes; 6 : no spermatozoa, no late spermatids, few early spermatids; 7: no spermatozoa, no late spermatids, many early spermatids; 8 : less than five spermatozoa per tubule, few late spermatids; 9: slightly impaired spermatogenesis, many late spermatids, disorganized epithelium; and 10: full spermatogenesis. ${ }^{16}$

\section{Western blot}

For steroidogenic acute regulatory (StAR) protein analysis, a crude mitochondrial preparation was acquired, as described in a previous study. ${ }^{17}$ Testis tissue was thoroughly washed in $2 \mathrm{~mL}$ of sucrose buffer $(0.25 \mathrm{M}$ sucrose, $10 \mathrm{mM}$ tris, $0.1 \mathrm{mM}$ ethylenediaminetetraacetic acid, $\mathrm{pH} 7.4$ ), and the homogenate was centrifuged at $600 \mathrm{rpm}$ for $15 \mathrm{~min}$. The cloudy supernatant, containing the mitochondria, was removed and transferred to another tube, which was then centrifuged at $12,000 \mathrm{rpm}$ for $15 \mathrm{~min}$. The resulting mitochondrial pellet was washed in sucrose buffer and recentrifuged at 12,000 rpm for $15 \mathrm{~min}$. Then, the pellet was resuspended in sucrose buffer, and the protein content was determined by using the Bradford assay for both lysates.

The samples were run on a $10 \%$ sodium dodecyl sulfate gel, transferred on a polyvinylidene fluoride membrane by using the Trans-Blot ${ }^{\circledR}$ SD semi-dry electrophoretic transfer cell (Bio-Rad, Hercules, CA, USA). Following this transfer, the membrane was blocked by using $10 \%$ nonfat milk for $1 \mathrm{~h}$ and incubated with StAR protein (Cell Signaling Technology, Beverly, MA, USA) for mitochondrial extracts at a 1:1,000 dilution at $4{ }^{\circ} \mathrm{C}$ overnight. Then, the membrane was washed with tris-buffered saline Tween (TBST) three times before adding a 1:5,000 dilution of secondary antibody for $1 \mathrm{~h}$. Following this, the membrane was washed three times with TBST and processed using an enhanced chemiluminescence substrate.
For CatSper analysis of the epididymal sperm, the above procedure was followed except that anti-CatSper antibodies (SC-33153; Santa Cruz Biotechnology Inc., Dallas, TX, USA) were used.

For the ER stress marker analysis, lysate was prepared from the testis tissue, and the protein content was determined by using the Bradford assay, following the procedure outlined above. The antibodies used were against glucose-regulated protein-78 (GRP-78; SC-376768), activating transcription factor (ATF; SC-22799), phosphorylated protein kinase RNA-like ER kinase (pPERK; SC-32577; Santa Cruz Biotechnology Inc.), and phosphorylated inositol-requiring transmembrane kinase/endoribonuclease (pIRE; ab-48187; Abcam $^{\circledR}$ PLC, Cambridge Science Park, Cambridge, UK).

\section{Statistical analysis}

All the data were expressed as mean \pm standard error. All statistical analyses were carried out by using SigmaPlot Version 12.0 (Systat Software, San Jose, CA, USA), with $P<0.05$ considered statistically significant.

\section{Results}

\section{Body and organ weights}

The weights of the body, testis, epididymis, seminal vesicle, prostate, and kidney were significantly less in CIS-treated groups than in the control group. Furthermore, body weight decreased in all of the CIS-treated groups but actually increased in the control group (Table 1).

\section{Sperm count and motility}

The sperm count and motility were significantly lower in the CIS-treated groups than in the control group (Table 2).

\section{Sperm apoptosis}

Sperm apoptosis was significantly higher in the CIS-treated groups than in the control group (Table 2).

\section{ROS/RNS and MDA}

ROS/RNS levels in the blood plasma were significantly higher in CIS-treated groups, except for the CIS-2 group, than in the control group. The plasma MDA level was also significantly higher in the CIS-6, CIS-8, and CIS-10 groups than in the control group (Table 3).

\section{Hematologic values}

The RBC count and $\mathrm{Hb}$ level were significantly higher in the CIS-6, CIS-8, and CIS-10 groups than in the control group. Furthermore, Hct was also significantly higher in the CIS-10 group than in the control group (Table 4). 
Table I Dose-dependent effects of cisplatin on body, testicular, epididymis, seminal vesicle, prostate and kidney weights

\begin{tabular}{lllllll}
\hline & Control & CIS-2 & CIS-4 & CIS-6 & CIS-8 & CIS-I0 \\
\hline Body weight (beginning; g) & $410.4 \pm 19.2 I$ & $381.6 \pm 6.83$ & $374.2 \pm 4.47$ & $372.1 \pm 5.83$ & $371.2 \pm 6.30$ & $392.1 \pm 4.82$ \\
Body weight (sacrifice; g) & $44 I .8 \pm I I .25$ & $348.2 \pm 5.60^{*}$ & $339.2 \pm 4.5 I^{*}$ & $319.5 \pm 5.54^{*}$ & $313.1 \pm 4.99^{*}$ & $310.7 \pm 5.66^{*}$ \\
Body weight (difference; g) & $31.4 \pm I I .60$ & $-33.4 \pm 7.54$ & $-35 \pm 5.78$ & $-52.6 \pm 10.62$ & $-58.1 \pm 10.17$ & $-81.4 \pm 4.41$ \\
Testis weight (g) & $2.21 \pm 0.02$ & $1.96 \pm 0.04^{\#}$ & $1.94 \pm 0.06^{\#}$ & $1.76 \pm 0.05^{*}$ & $1.67 \pm 0.07^{\#}$ & $1.62 \pm 0.03^{*}$ \\
Epididymis weight (g) & $0.8 \pm 0.04$ & $0.63 \pm 0.02^{\#}$ & $0.61 \pm 0.02^{*}$ & $0.58 \pm 0.02^{*}$ & $0.57 \pm 0.02^{*}$ & $0.52 \pm 0.03^{*}$ \\
Seminal vesicle weight (g) & $0.91 \pm 0.05$ & $0.65 \pm 0.02^{\#}$ & $0.53 \pm 0.04^{*}$ & $0.42 \pm 0.02^{*}$ & $0.42 \pm 0.04^{\#}$ & $0.39 \pm 0.02^{\#}$ \\
Prostate weight (g) & $1.35 \pm 0.12$ & $1.25 \pm 0.05$ & $1.24 \pm 0.05$ & $0.68 \pm 0.04^{\#}$ & $0.61 \pm 0.08^{\#}$ & $0.6 \pm 0.05^{\#}$ \\
Kidney weight (g) & $1.45 \pm 0.02$ & $1.29 \pm 0.03^{\#}$ & $1.39 \pm 0.03$ & $1.57 \pm 0.06$ & $1.62 \pm 0.16$ & $1.34 \pm 0.04^{\#}$ \\
\hline
\end{tabular}

Notes: Data are expressed as mean \pm standard error. ${ }^{*} P<0.001$ versus control group, ${ }^{*} P<0.05$ versus control group.

Abbreviations: CIS-2, cisplatin $2 \mathrm{mg} / \mathrm{kg}$ i.p.; CIS-4, cisplatin $4 \mathrm{mg} / \mathrm{kg}$ i.p.; CIS-6, cisplatin $6 \mathrm{mg} / \mathrm{kg}$ i.p.; CIS-8, cisplatin $8 \mathrm{mg} / \mathrm{kg}$ i.p.; CIS-I0, cisplatin $10 \mathrm{mg} / \mathrm{kg}$ i.p.; i.p., intraperitoneally.

Table 2 Dose-dependent effects of cisplatin on sperm count, motility, and apoptosis

\begin{tabular}{lllllll}
\hline & Control & CIS-2 & CIS-4 & CIS-6 & CIS-8 & CIS-10 \\
\hline $\begin{array}{l}\text { Epididymis sperm } \\
\text { count }\left(10^{6}\right)\end{array}$ & $33.1 \pm 1.59$ & $34.75 \pm 2.23$ & $25.25 \pm 2.27^{\#}$ & $32.7 \pm 1.29$ & $23.3 \pm 2.09^{\#}$ & $28.9 \pm 4.57^{\#}$ \\
$\begin{array}{l}\text { Epididymis sperm } \\
\text { motility (\%) }\end{array}$ & $43.02 \pm 0.43$ & $10.93 \pm 5.07^{*}$ & $12.04 \pm 4.03^{*}$ & $25.6 \pm 3.94^{\#}$ & $18.51 \pm 3.76^{\#}$ & $11.05 \pm 8.24^{*}$ \\
$\begin{array}{l}\text { Epididymis sperm } \\
\text { apoptosis (\%) }\end{array}$ & $8.58 \pm 0.72$ & $9.09 \pm 1.03$ & $9.38 \pm 0.92$ & $12.35 \pm 1.05$ & $14.55 \pm 2.05^{\#}$ & $16.64 \pm 1.03^{\#}$ \\
\hline
\end{tabular}

Notes: Data are expressed as mean \pm standard error. ${ }^{*} P<0.001$, versus control group, ${ }^{*} P<0.05$ versus control group.

Abbreviations: CIS-2, cisplatin $2 \mathrm{mg} / \mathrm{kg}$ i.p.; CIS-4, cisplatin $4 \mathrm{mg} / \mathrm{kg}$ i.p.; CIS-6, cisplatin $6 \mathrm{mg} / \mathrm{kg}$ i.p.; CIS-8, cisplatin 8 mg/kg i.p.; CIS-10, cisplatin I0 mg/kg i.p.; i.p., intraperitoneally.

Table 3 Dose-dependent effects of cisplatin on ROS/RNS and MDA in blood plasma

\begin{tabular}{lllllll}
\hline & Control & CIS-2 & CIS-4 & CIS-6 & CIS-8 & CIS-10 \\
\hline ROS/RNS (nM DCF/mL) & $3.36 \pm 2.19$ & $10.12 \pm 1.94$ & $15.13 \pm 3.44^{\#}$ & $15.79 \pm 2.14^{\#}$ & $16.68 \pm 0.010^{\#}$ & $16.70 \pm 3.21^{\#}$ \\
MDA $(\mathrm{nM} / \mathrm{mL})$ & $1.01 \pm 0.04$ & $1.03 \pm 0.013$ & $1.06 \pm 0.05$ & $1.57 \pm 0.16^{\#}$ & $1.605 \pm 0.264^{\#}$ & $1.96 \pm 0.0292^{\#}$ \\
\hline
\end{tabular}

Notes: Data are expressed as mean \pm standard error. $\# p<0.05$ versus control group.

Abbreviations: CIS-2, cisplatin $2 \mathrm{mg} / \mathrm{kg}$ i.p.; CIS-4, cisplatin $4 \mathrm{mg} / \mathrm{kg}$ i.p.; CIS-6, cisplatin $6 \mathrm{mg} / \mathrm{kg}$ i.p.; CIS-8, cisplatin $8 \mathrm{mg} / \mathrm{kg}$ i.p.; CIS-10, cisplatin $10 \mathrm{mg} / \mathrm{kg}$ i.p.; i.p., intraperitoneally; DCF, dichlorofluorescin; MDA, malondialdehyde; RNS, reactive nitrogen species; ROS, reactive oxygen species.

Table 4 Dose-dependent effects of cisplatin on RBC count, hemoglobin, and hematocrit

\begin{tabular}{lllllll}
\hline & Control & CIS-2 & CIS-4 & CIS-6 & CIS-8 & CIS-10 \\
\hline RBC count $\times 10^{6}(\mu \mathrm{L})$ & $7.302 \pm 0.09$ & $7.571 \pm 0.144$ & $7.607 \pm 0.206$ & $8.375 \pm 0.198^{\#}$ & $9.592 \pm 0.507^{\#}$ & $9.91 \pm 0.42^{*}$ \\
Hemoglobin $(\mathrm{g} / \mathrm{dL})$ & $13.52 \pm 0.124$ & $14.08 \pm 0.252$ & $14.31 \pm 0.421$ & $15.6 \pm 0.343^{\#}$ & $17.68 \pm 1.224^{\#}$ & $18.625 \pm 0.862^{*}$ \\
Hematocrit $(\%)$ & $41.24 \pm 0.495$ & $41.33 \pm 0.69$ & $41.6 \pm 1.104$ & $44.01 \pm 0.921$ & $47.48 \pm 2.841$ & $51.025 \pm 2.097^{\#}$ \\
\hline
\end{tabular}

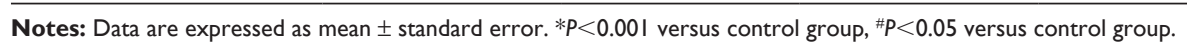

Abbreviations: CIS-2, cisplatin $2 \mathrm{mg} / \mathrm{kg}$ i.p.; CIS-4, cisplatin $4 \mathrm{mg} / \mathrm{kg}$ i.p.; CIS-6, cisplatin $6 \mathrm{mg} / \mathrm{kg}$ i.p.; CIS-8, cisplatin $8 \mathrm{mg} / \mathrm{kg}$ i.p.; CIS-10, cisplatin $10 \mathrm{mg} / \mathrm{kg}$ i.p.; i.p., intraperitoneally; RBC, red blood cell. 
A

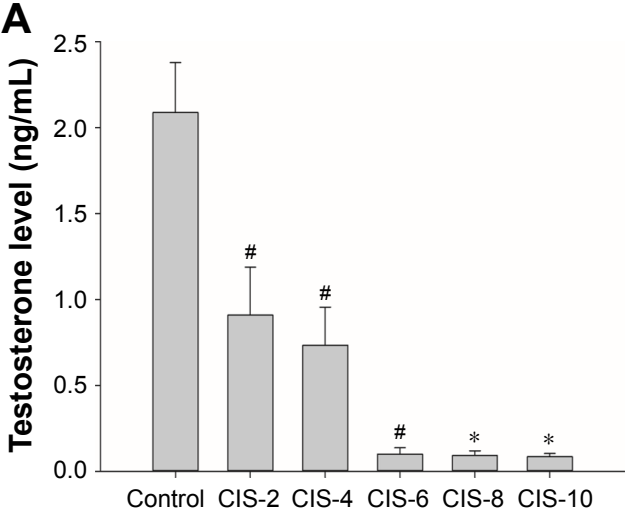

B

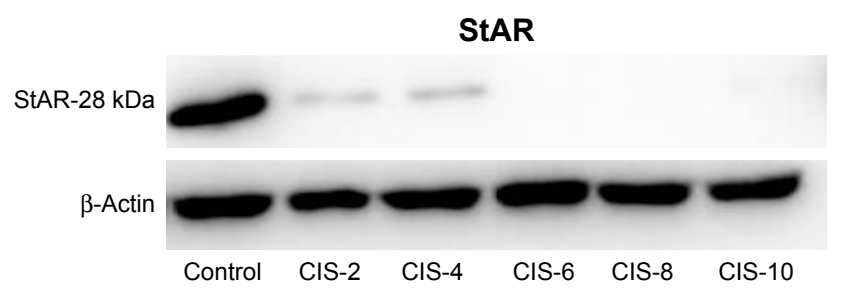

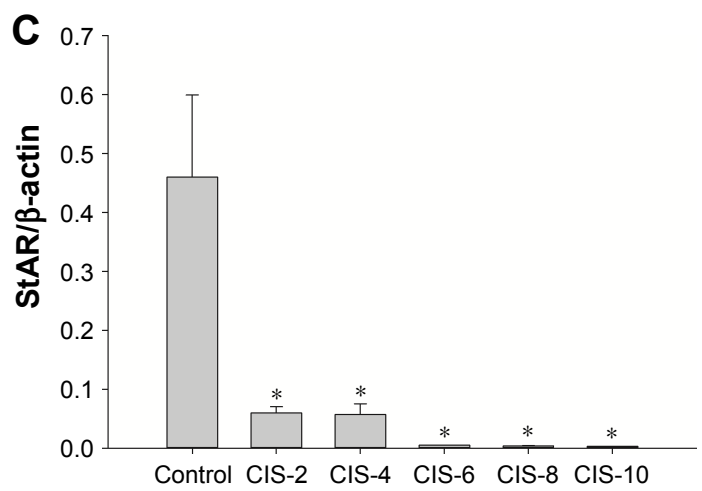

Figure I Effect of cisplatin on testosterone and testicular tissue.

Notes: (A) Total testosterone level; (B) Western blot of StAR protein; (C) StAR protein. Data are expressed as mean \pm standard error. $* P<0.00 I$ versus control group, ${ }^{\#} P<0.05$ versus control group.

Abbreviations: CIS-2, cisplatin 2 mg/kg i.p.; CIS-4, cisplatin 4 mg/kg i.p.; CIS-6, cisplatin 6 mg/kg i.p.; CIS-8, cisplatin 8 mg/kg i.p.; CIS-I0, cisplatin I0 mg/kg i.p.; i.p., intraperitoneally; StAR, steroidogenic acute regulatory.

\section{Plasma testosterone and StAR protein}

There was a significant decrease in the plasma testosterone level for each CIS-treated group compared with the control group (Figure 1A). The concentration of StAR protein in the testis tissue was also significantly lower in the CIS-treated groups than in the control group (Figure 1B and C).

\section{Epididymal sperm CatSper}

Epididymal sperm CatSper was significantly lower in the CIS-6, CIS-8, and CIS-10 groups than in the control group (Figure 2A and B).

\section{ER stress markers}

The ER stress markers GRP-78 (Figure 3A and E), ATF (Figure 3B and F), pIRE (Figure 3C and G), and pPERK (Figure 3D and $\mathrm{H}$ ) were significantly higher in the CIS-6, CIS-8, and CIS-10 groups than in the control group.

\section{Renal index, plasma BUN, and histopathology of the kidney}

The renal index was significantly higher in the CIS-6 and CIS-8 groups than in the control group (Table 5). Plasma BUN

\section{A}
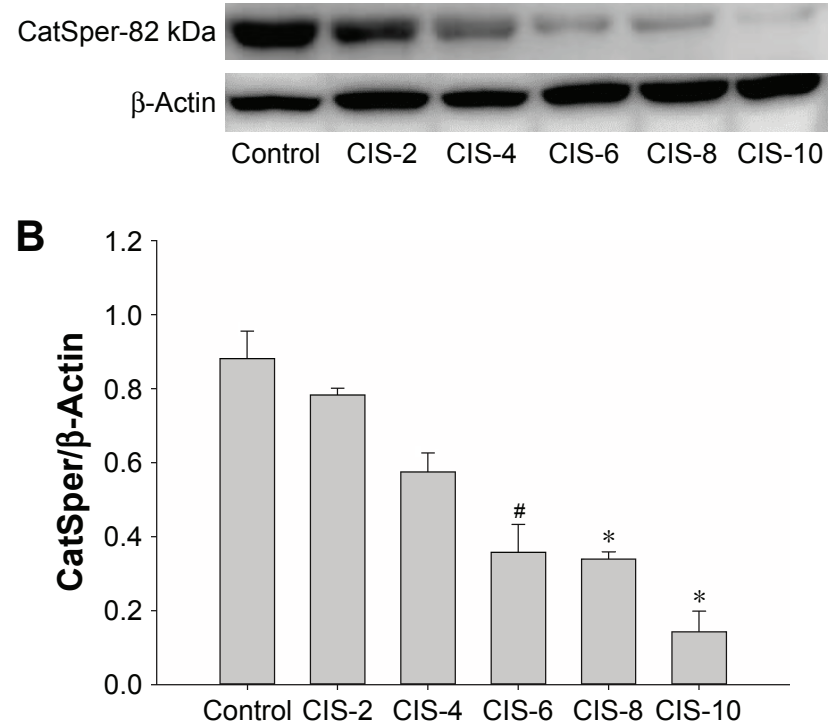

Figure 2 Effect of cisplatin on epididymal sperm.

Notes: (A) Western blot of CatSper; (B) CatSper protein. Data are expressed as mean \pm standard error. ${ }^{* P}<0.001$ versus control group, ${ }^{\sharp} P<0.05$ versus control group.

Abbreviations: CIS-2, cisplatin $2 \mathrm{mg} / \mathrm{kg}$ i.p.; CIS-4, cisplatin $4 \mathrm{mg} / \mathrm{kg}$ i.p.; CIS-6, cisplatin $6 \mathrm{mg} / \mathrm{kg}$ i.p.; CIS-8, cisplatin $8 \mathrm{mg} / \mathrm{kg}$ i.p.; CIS-10, cisplatin $10 \mathrm{mg} / \mathrm{kg}$ i.p.; i.p., intraperitoneally. 
A

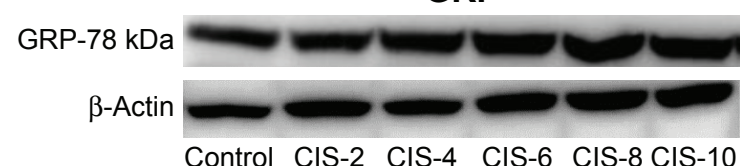

C

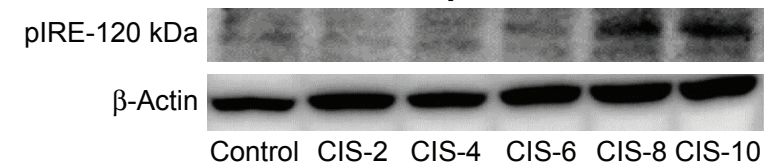

E
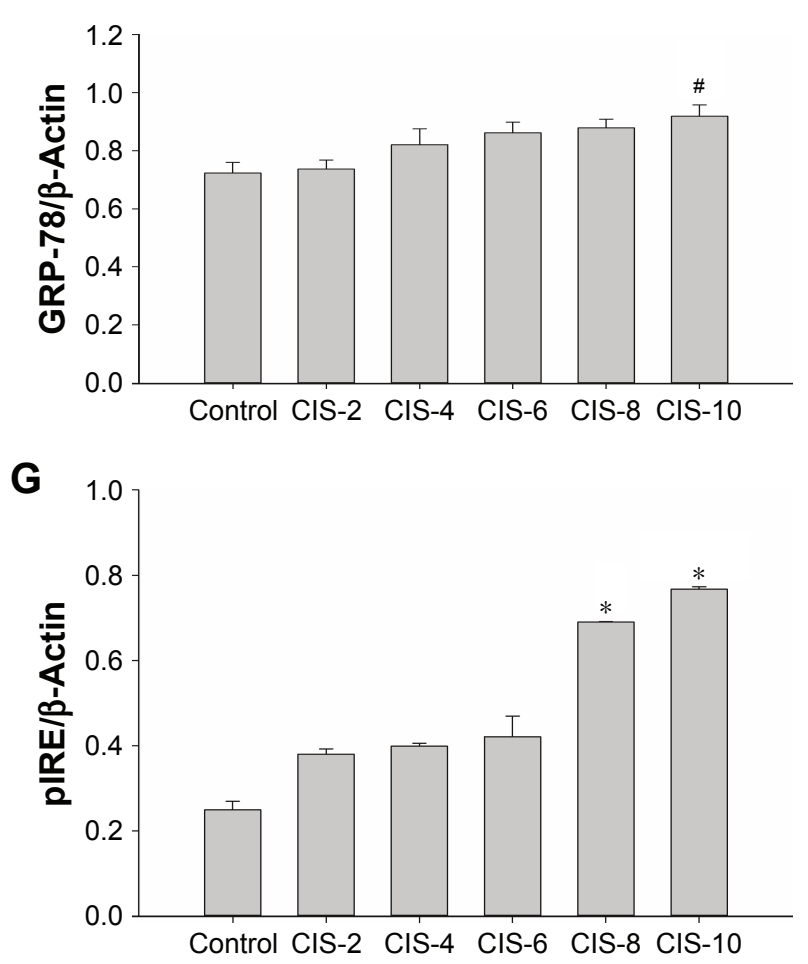

B

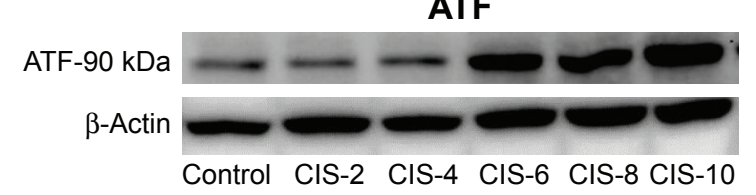

D

pPERK-125 kDa

$\beta$-Actin

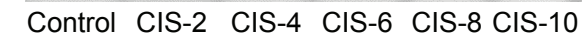

$\mathbf{F}$

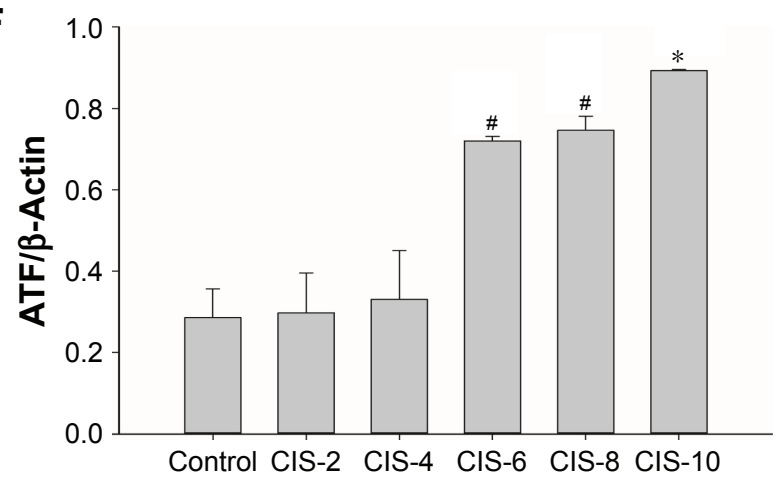

H

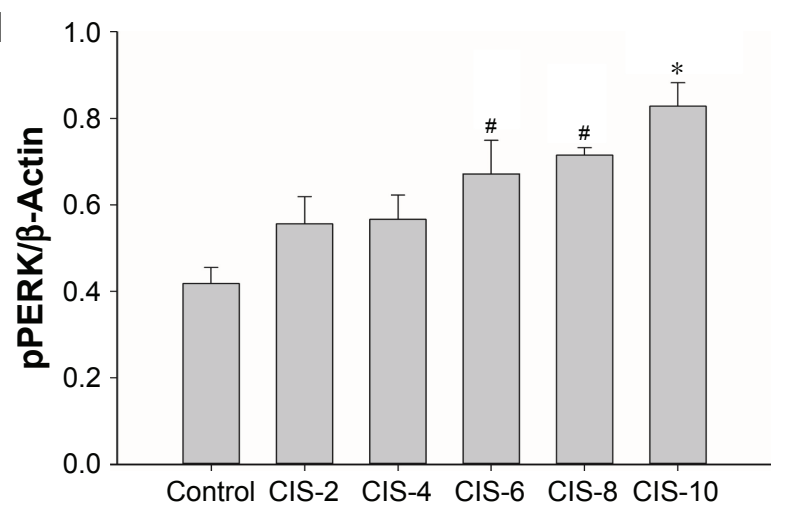

Figure 3 Effect of cisplatin on endoplasmic reticulum stress markers.

Notes: (A) Western blot of GRP-78; (B) Western blot of ATF; (C) Western blot of pIRE; (D) Western blot of pPERK; (E) GRP-78 protein; (F) ATF protein; (G) pIRE protein; $(\mathbf{H})$ PPERK protein. Data are expressed as mean \pm standard error. $* P<0.00$ I versus control group, ${ }^{\#} P<0.05$ versus control group.

Abbreviations: ATF, activating transcription factor; CIS-2, cisplatin 2 mg/kg i.p.; CIS-4, cisplatin 4 mg/kg i.p.; CIS-6, cisplatin 6 mg/kg i.p.; CIS-8, cisplatin 8 mg/kg i.p.; CIS- I0, cisplatin 10 mg/kg i.p.; GRP-78, glucose-regulated protein-78; i.p., intraperitoneally; pIRE, phosphorylated inositol-requiring transmembrane kinase/endoribonuclease; pPERK, phosphorylated protein kinase RNA-like endoplasmic reticulum kinase.

level was also significantly higher in the CIS-4, CIS-6, CIS-8, and CIS-10 groups than in the control group (Table 5). The kidney tissue exhibited a normal arrangement of the glomerulus, proximal tubules, and epithelial brush borders in the control group, with no histopathologic lesions, whereas these were abnormal in the CIS-treated groups (Figure 4A). The tubular necrosis score was also significantly higher in the CIS-treated groups than in the control group (Table 5).

Table 5 Dose-dependent effects of cisplatin on renal index, BUN, and renal tubular necrosis

\begin{tabular}{lllllll}
\hline & Control & CIS-2 & CIS-4 & CIS-6 & CIS-8 & CIS-10 \\
\hline Renal index (\%) & $0.33 \pm 0.01 \mathrm{I}$ & $0.37 \pm 0.008$ & $0.41 \pm 0.007$ & $0.49 \pm 0.018^{*}$ & $0.50 \pm 0.049 *$ & $0.41 \pm 0.0124$ \\
BUN (mg/dL) & $22.4 \pm 0.678$ & $32.4 \pm 4.167$ & $152.9 \pm 19.234^{*}$ & $302.5 \pm 23.133^{*}$ & $407.2 \pm 23.483^{*}$ & $398.25 \pm 22.555^{*}$ \\
Tubular necrosis (\%) & $1.33 \pm 0.33$ & $12 \pm 0.58^{*}$ & $27.33 \pm 1.45^{*}$ & $53.33 \pm 2.03^{*}$ & $77.67 \pm 1.45^{*}$ & $84.33 \pm 1.76^{*}$ \\
\hline
\end{tabular}

Notes: Data are expressed as mean \pm standard error. $* P<0.001$ versus control group, ${ }^{\sharp} P<0.05$ versus control group.

Abbreviations: BUN, blood urea nitrogen; CIS-2, cisplatin 2 mg/kg i.p.; CIS-4, cisplatin 4 mg/kg i.p.; CIS-6, cisplatin 6 mg/kg i.p.; CIS-8, cisplatin 8 mg/kg i.p.; CIS-I0, cisplatin $10 \mathrm{mg} / \mathrm{kg}$ i.p.; i.p., intraperitoneally. 

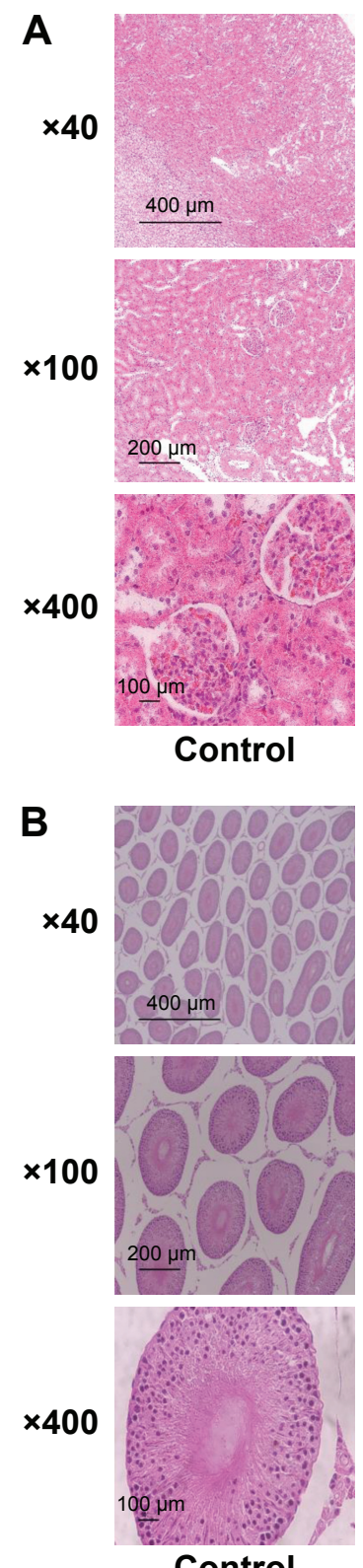

Control
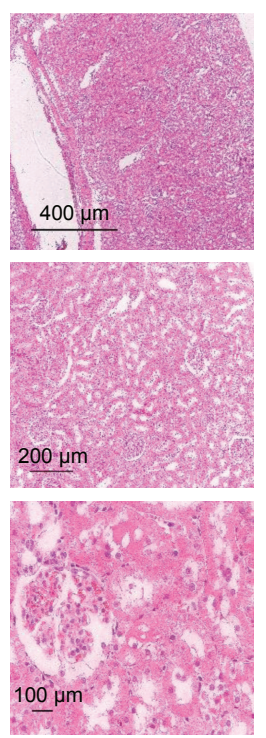

CIS-2
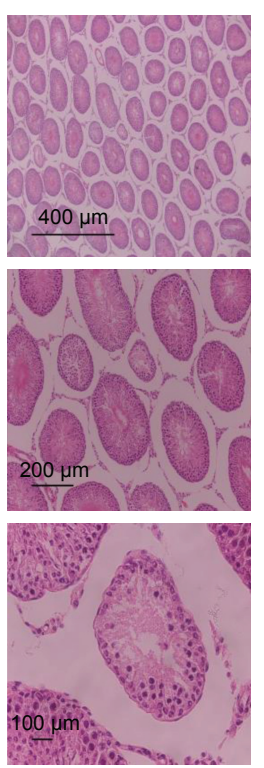

CIS-2
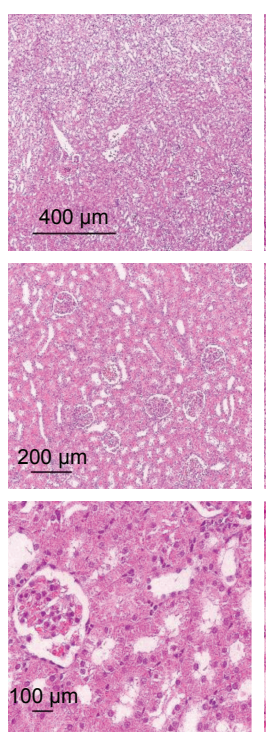

CIS-4
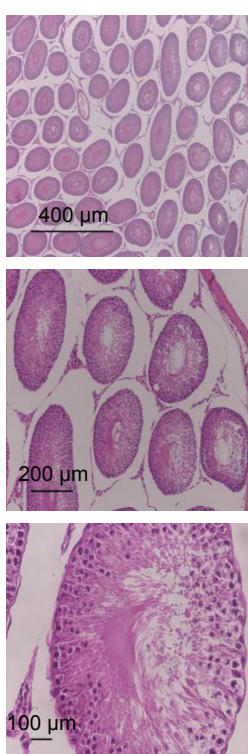

CIS-4
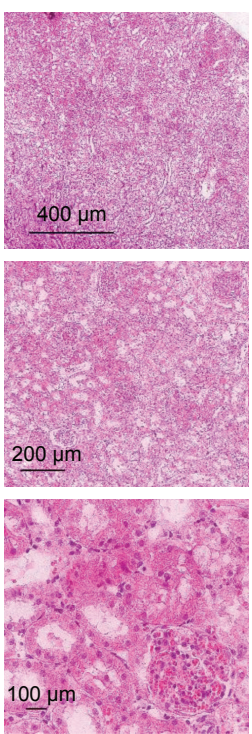

CIS-6
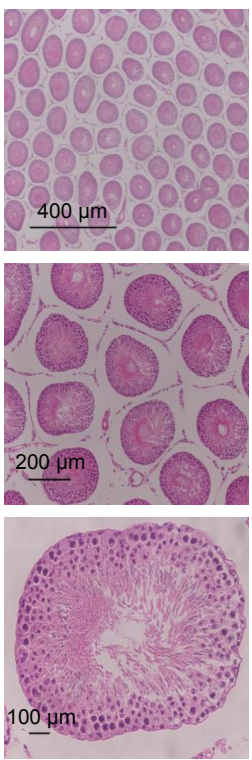

CIS-6
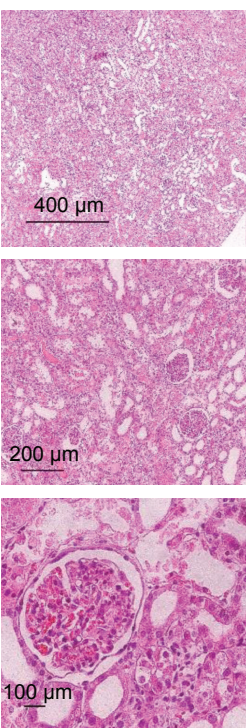

CIS-8
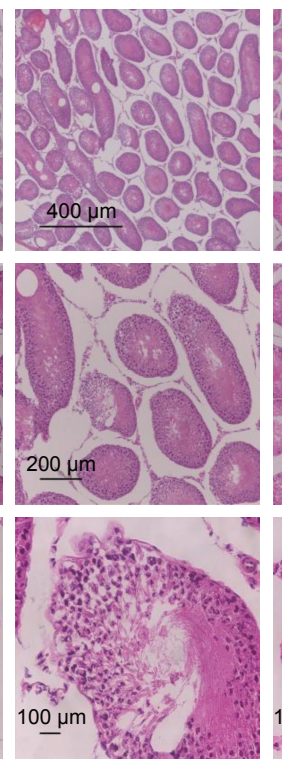

CIS-8
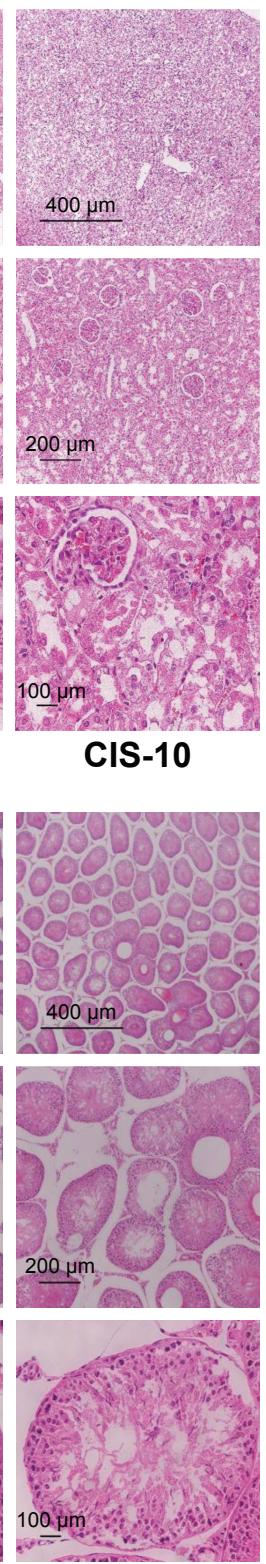

CIS-10

Figure 4 Light micrographs of tissue stained with hematoxylin and eosin $(\times 400)$. Notes: (A) Kidney; (B) testis.

\section{Histopathology of the testis}

The testicular tissue showed a normal arrangement of germinal cells, Sertoli cells, and Leydig cells in the control group, with no histopathologic lesions, whereas these were abnormal in the CIS-treated groups (Figure 4B). The spermatogenic cell density and Johnson's score were significantly lower in the CIS-4, CIS-6, CIS-8, and CIS-10 groups than in the control group (Table 6).

Table 6 Dose-dependent effects of cisplatin in spermatogenic cell density and Johnsen's score of seminiferous tubules

\begin{tabular}{lllllll}
\hline & Control & CIS-2 & CIS-4 & CIS-6 & CIS-8 & CIS-10 \\
\hline Spermatogenic cell density & $0.45 \pm 0.016$ & $0.43 \pm 0.015$ & $0.36 \pm 0.012^{*}$ & $0.30 \pm 0.010^{*}$ & $0.22 \pm 0.007^{*}$ & $0.18 \pm 0.017^{*}$ \\
Johnsen's score & $8.67 \pm 0.33$ & $7.33 \pm 0.33$ & $5.67 \pm 0.33^{*}$ & $5.33 \pm 0.33^{*}$ & $4.67 \pm 0.33^{*}$ & $3.67 \pm 0.33^{*}$ \\
\hline
\end{tabular}

Notes: Data are expressed as mean \pm standard error. $* P<0.001$ versus control group, ${ }^{\sharp} P<0.05$ versus control group.

Abbreviations: CIS-2, cisplatin 2 mg/kg i.p.; CIS-4, cisplatin 4 mg/kg i.p.; CIS-6, cisplatin 6 mg/kg i.p.; CIS-8, cisplatin 8 mg/kg i.p.; CIS- 10 , cisplatin 10 mg/kg i.p.; i.p., intraperitoneally. 


\section{Discussion}

The rats treated with CIS exhibited significantly lower body weight and reproductive organ weight than the untreated control animals. CIS is a potent anticancer drug that has been shown to induce testicular disintegration, sperm dysfunction, germ cell apoptosis, and abnormalities in the Leydig cells, ${ }^{18,19}$ as well as toxicity due to membrane rigidification, lipid peroxidation, and oxidative damage in rats and a reduction in antioxidants. ${ }^{5,20}$ These toxic effects result from CIS-induced oxidative stress caused by elevated ROS and RNS levels. CIS also increases lipid peroxidation by markedly increasing the MDA level in a dose-dependent manner.

Furthermore, the StAR protein level, which was first identified in mid-1980s, has been shown to be important for transferring cholesterol, ${ }^{11,21}$ from the outer to the inner mitochondrial membrane to synthesize testosterone. ${ }^{22}$ StAR protein was significantly lower in the CIS-treated groups than in the control group, thus interfering with testosterone production. The total testosterone level decreased significantly in the CIS-treated rats compared with the control rats as a result of damage caused to the Leydig cells. ${ }^{10}$

CatSper channels (or $\mathrm{Ca}^{2+}$ ion channels) were significantly lower in the sperm cells of CIS-treated rats. These channels mediate sperm hyperactivation, ${ }^{23}$ with their gene expression levels being significantly lower in males with low sperm motility than in those with normal fertility. ${ }^{24}$ Indeed, a recent study reported that male CatSper knockout mice displayed infertility due to a lack of hyperactivated sperm motility, despite the presence of normal sperm counts and motility. ${ }^{25}$ Similarly, in the present study, CIS-treated male rats exhibited lower sperm counts and motility.

By contrast, the renal index, BUN, and tubular necrosis were higher in CIS-treated rats than in untreated control animals. These findings are similar to those in a previous study. ${ }^{26}$ Histologic examination of the kidneys revealed severe degeneration in the glomeruli and proximal and distal

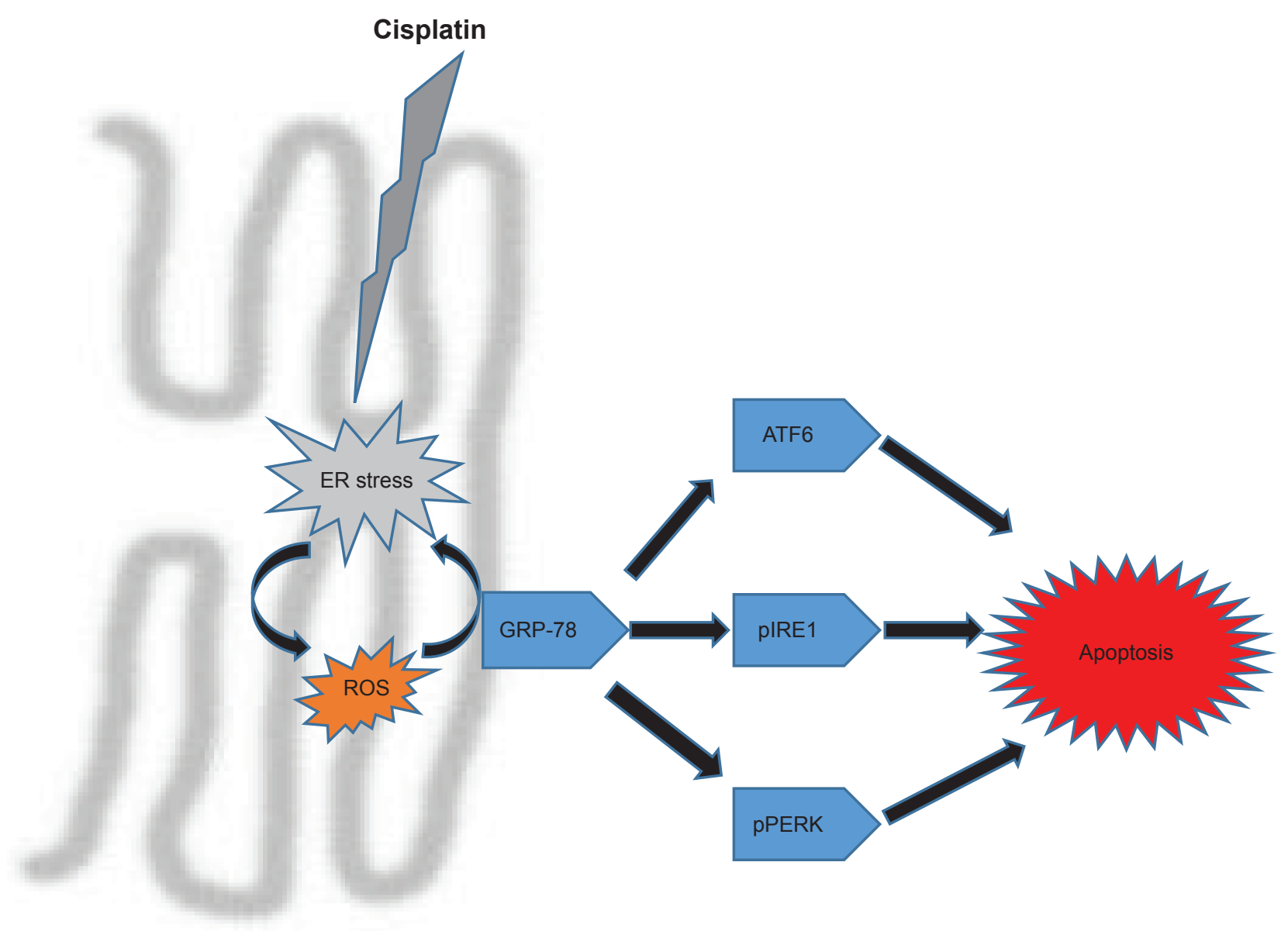

\section{Endoplasmic reticulum}

Figure 5 Relation between cisplatin dose-dependent effect on ROS and ER stress.

Abbreviations: ATF, activating transcription factor; ER, endoplasmic reticulum; pIRE, inositol-requiring transmembrane kinase/endoribonuclease; pPERK, phosphorylated protein kinase RNA-like endoplasmic reticulum kinase; ROS, reactive oxygen species. 
tubules, as well as proteinaceous casts in the tubular lumen and necrosis, similar with earlier findings. ${ }^{8,27}$ Furthermore, the spermatogenic cell density and Johnsen's score were lower in CIS-treated rats, and testicular disintegration and germ cell apoptosis were observed. ${ }^{11}$

Finally, all the ER stress markers measured were significantly higher in the higher dose CIS-treated groups than in the control group. ER stress is triggered by an accumulation of unfolded or misfolded proteins caused by oxidative stress, iron imbalance, $\mathrm{Ca}^{2+}$ leakage, protein overload, and hypoxia. ${ }^{28}$ This leads to activation of an integrated program known as the unfolded protein response (UPR) via three signaling pathways from the ER stress sensors: ATF6, pPERK, and pIRE1. ${ }^{29}$ pPERK and pIRE1 signaling pathways lead to apoptosis, whereas evidence has been lacking for ATF6 in this regard, ${ }^{30}$ but a recent study support a role for ATF6 in apoptosis. ${ }^{31}$ The present study also had found a higher level of ATF6 in CIS-treated rats.

Chemotherapy has been shown to cause anemia; ${ }^{32}$ however, in the present study, CIS treatment over a 5-day period caused an increase in $\mathrm{RBC}, \mathrm{Hb}$, and Hct levels, similar to the findings of Unami et al, where RBC, Hct, and Hb levels increased in rats within 4 days of CIS administration due to increased erythropoietin. ${ }^{9}$

In the present study, the toxic effects of increasing doses of CIS on the blood, kidneys, and genitals of rats over a constant period of time were examined. It was found that with higher doses of CIS, body and organ weights decreased and oxidative stress markers (ROS/RNS and MDA) increased along with increasing ER stress markers. An important relationship between ROS-mediated ER stress and CIS (Figure 5) was revealed. The ability of ROS to evoke ER stress after CIS administration was investigated, and it was found that the UPR effectors GRP-78, pIRE1 $\alpha$, pPERK, and ATF6 were triggered in a ROS-dependent manner.

Degeneration of the glomerulus and tubules in the kidney was detected microscopically. In addition, the level of CatSper in the epididymal sperm decreased, and the levels of ER stress proteins increased with increasing doses of CIS in rats. Therefore, it is likely that CIS-induced infertility results from a lower number of $\mathrm{Ca}^{2+}$ ion channels.

The dose of CIS used in this study cannot be translated to humans, where the dose used varies according to the type of cancer being treated. However, these findings show that a high dose of CIS is toxic in a rat model, demonstrating that in a clinical situation, the recommended dose of CIS should be used according to the advice of clinicians, the type of cancer, and the desire for future fertility.

\section{Conclusion}

This study demonstrated that although CIS is useful for chemotherapy, a higher dose induces oxidative stress, which has a lethal effect on the body, vital organs, and testis. Treatment with CIS was shown to increase the levels of ER stress markers and reduce the numbers of CatSper in the sperm, which are required for hyperactivated sperm motility.

\section{Acknowledgments}

The authors thank Mrs Back Yun Oak and the members of the Laboratory of Experimental Urology for helpful discussions. This study was supported by grants from the Korea Healthcare Technology R\&D Project, Ministry for Health, Welfare \& Family Affairs, Republic of Korea (HI14C0018). The Korea Healthcare Technology R\&D Project, Ministry for Health, Welfare \& Family Affairs, Republic of Korea, had no role in the design or conduct of the study; collection, management, analysis, and interpretation of the data; or preparation, review, or approval of the manuscript. The content of this article is solely the responsibility of the authors and does not necessarily represent the official views of the Korea Healthcare Technology R\&D Project, Ministry for Health, Welfare \& Family Affairs, Republic of Korea.

\section{Disclosure}

Jong Kwan Park certifies that all conflicts of interest, including specific financial interests and relationships and affiliations relevant to the subject matter or materials discussed in the manuscript (eg, employment/affiliation, grants or funding, consultancies, honoraria, stock ownership or options, expert testimony, royalties, or patents filed, received, or pending) are as follows: Jong Kwan Park is a consultant and speaker for and has received unconditional research grants from Dong-A Pharmaceutical Company, Yong-in, Kyounggi, Republic of Korea. The other authors report no conflicts of interest in this work.

\section{References}

1. Prestayko AW, D'Aoust JC, Issell BF, Crooke ST. Cisplatin (cisdiamminedichloroplatinum II). Cancer Treat Rev. 1979;6(1):17-39.

2. Kelland L. The resurgence of platinum-based cancer chemotherapy. Nat Rev Cancer. 2007;7(8):573-584

3. Burchenal JH, Kalaher K, Dew K, Lokys L. Rationale for development of platinum analogs. Cancer Treat Rep. 1979;63(9-10):1493-1498.

4. Liao Y, Lu X, Lu C, Li G, Jin Y, Tang H. Selection of agents for prevention of cisplatin-induced hepatotoxicity. Pharmacol Res. 2008;57(2): $125-131$

5. Atasayar S, Gürer-Orhan H, Orhan H, Gürel B, Girgin G, Ozgüneş H. Preventive effect of aminoguanidine compared to vitamin $\mathrm{E}$ and $\mathrm{C}$ on cisplatin-induced nephrotoxicity in rats. Exp Toxicol Pathol. 2009;61(1) $23-32$. 
6. Ku JY, Park NC, Jeon TG, Park HJ. Semen analysis in cancer patients referred for sperm cryopreservation before chemotherapy over a 15-year period in Korea. World J Mens Health. 2015;33(1):8-13.

7. Koc A, Duru M, Ciralik H, Akcan R, Sogut S. Protective agent, erdosteine, against cisplatin-induced hepatic oxidant injury in rats. $\mathrm{Mol}$ Cell Biochem. 2005;278(1-2):79-84.

8. Işeri S, Ercan F, Gedik N, Yüksel M, Alican I. Simvastatin attenuates cisplatin-induced kidney and liver damage in rats. Toxicology. 2007; 230(2-3):256-264.

9. Unami A, Nishina N, Terai T, et al. Effects of cisplatin on erythropoietin production in rats. J Toxicol Sci. 1996;21(3):157-165.

10. Vawda AI. Effect of testosterone on cisplatin-induced testicular damage. Arch Androl. 1994;32(1):53-57.

11. Soni KK, Zhang LT, You JH, et al. The effects of MOTILIPERM on cisplatin induced testicular toxicity in Sprague-Dawley rats. Cancer Cell Int. 2015;15:121.

12. Ateşşahin A, Karahan I, Türk G, Gür S, Yilmaz S, Ceribaşi AO. Protective role of lycopene on cisplatin-induced changes in sperm characteristics, testicular damage and oxidative stress in rats. Reprod Toxicol. 2006;21(1):42-47.

13. Quill TA, Ren D, Clapham DE, Garbers DL. A voltage-gated ion channel expressed specifically in spermatozoa. Proc Natl Acad Sci U S A. 2001;98(22):12527-12531.

14. Qi H, Moran MM, Navarro B, et al. All four CatSper ion channel proteins are required for male fertility and sperm cell hyperactivated motility. Proc Natl Acad Sci US A. 2007;104(4):1219-1223.

15. Sung MJ, Kim DH, Jung YJ, et al. Genistein protects the kidney from cisplatin-induced injury. Kidney Int. 2008;74(12):1538-1547.

16. Yoshida A, Miura K, Shirai M. Evaluation of seminiferous tubule scores obtained through testicular biopsy examinations of nonobstructive azoospermic men. Fertil Steril. 1997;68(3):514-518.

17. Clark BJ, Wells J, King SR, Stocco DM. The purification, cloning, and expression of a novel luteinizing hormone-induced mitochondrial protein in MA-10 mouse Leydig tumor cells. Characterization of the steroidogenic acute regulatory protein (StAR). J Biol Chem. 1994;269(45): 28314-28322.

18. Cherry SM, Hunt PA, Hassold TJ. Cisplatin disrupts mammalian spermatogenesis, but does not affect recombination or chromosome segregation. Mutat Res. 2004;564(2):115-128.

19. Meistrich ML, Finch M, da Cunha MF, Hacker U, Au WW. Damaging effects of fourteen chemotherapeutic drugs on mouse testis cells. Cancer Res. 1982;42(1):122-131.
20. Martins NM, Santos NA, Curti C, Bianchi ML, Santos AC. Cisplatin induces mitochondrial oxidative stress with resultant energetic metabolism impairment, membrane rigidification and apoptosis in rat liver. J Appl Toxicol. 2008;28(3):337-344.

21. Pon LA, Orme-Johnson NR. Acute stimulation of steroidogenesis in corpus luteum and adrenal cortex by peptide hormones. Rapid induction of a similar protein in both tissues. J Biol Chem. 1986;261(14): 6594-6599.

22. Stocco DM, Wells J, Clark BJ. The effects of hydrogen peroxide on steroidogenesis in mouse Leydig tumor cells. Endocrinology. 1993;133(6): 2827-2832.

23. Brenker C, Goodwin N, Weyand I, et al. The CatSper channel: a polymodal chemosensor in human sperm. EMBO J. 2012;31(7):1654-1665.

24. Nikpoor P, Mowla SJ, Movahedin M, Ziaee SA, Tiraihi T. CatSper gene expression in postnatal development of mouse testis and in subfertile men with deficient sperm motility. Hum Reprod. 2004;19(1):124-128.

25. Jin J, Jin N, Zheng H, et al. Catsper3 and Catsper4 are essential for sperm hyperactivated motility and male fertility in the mouse. Biol Reprod. 2007;77(1):37-44.

26. Gao Z, Liu G, Hu Z, et al. Grape seed proanthocyanidin extract protects from cisplatin-induced nephrotoxicity by inhibiting endoplasmic reticulum stress-induced apoptosis. Mol Med Rep. 2014;9(3):801-807.

27. Palipoch S, Punsawad C. Biochemical and histological study of rat liver and kidney injury induced by Cisplatin. J Toxicol Pathol. 2013;26(3): 293-299.

28. Schroder M, Kaufman RJ. The mammalian unfolded protein response. Annu Rev Biochem. 2005;74:739-789.

29. Kadowaki H, Nishitoh H. Signaling pathways from the endoplasmic reticulum and their roles in disease. Genes (Basel). 2013;4(3): 306-333.

30. Wang M, Kaufman RJ. The impact of the endoplasmic reticulum protein-folding environment on cancer development. Nat Rev Cancer. 2014;14(9):581-597.

31. Han X, Zhang P, Jiang R, Xia F, Li M, Guo FJ. Explore on the effect of ATF6 on cell growth and apoptosis in cartilage development. Histochem Cell Biol. 2014;142(5):497-509.

32. Wood PA, Hrushesky WJ. Cisplatin-associated anemia: an erythropoietin deficiency syndrome. J Clin Invest. 1995;95(4):1650-1659.
Drug Design, Development and Therapy

\section{Publish your work in this journal}

Drug Design, Development and Therapy is an international, peerreviewed open-access journal that spans the spectrum of drug design and development through to clinical applications. Clinical outcomes, patient safety, and programs for the development and effective, safe, and sustained use of medicines are the features of the journal, which

\section{Dovepress}

has also been accepted for indexing on PubMed Central. The manuscript management system is completely online and includes a very quick and fair peer-review system, which is all easy to use. Visit http://www.dovepress.com/testimonials.php to read real quotes from published authors. 